$621.822 .7 .034 .4: 621.313 .333$

\title{
Noise of Ball Bearing in Electric Motor*
}

\author{
By Teruo IgARAshr**
}

There are many performances of electric motors equipped with rolling bearings, and one of the most important performances is running noise. Especially, for a small three phase a-c induction motor, quiet running is demanded.

However, the component noises in the motor noise are not well known and the influences of ball bearing on the motor noise are not made clear. Therefore, to abate the motor noise, we must study it.

So, in the first place, the noise of a small three phase a-c induction motor was divided into several component noises, and ones influenced by ball bearings were found out; next, the influences of ball bearings were examined, lastly the causes of the influences were made clear in the present paper.

As a result of the above studies, we could establish the most suitable treatment of ball bearings theoretically, and further obtain new knowledges on fitted ball bearing noise.

\section{Introduction}

There are many performances of electric motors equipped with rolling bearings, and one of the most important performances is running noise. Especially, for small three phase induction motors equipped with ball bearings, quiet running is demanded.

Now, it is known that noise of small three phase induction motors is composed of several component noises, and a certain one of them is influenced by ball bearings ${ }^{(1)(2)}$. However, these component noises are not well defined and the influences of ball bearings are not made clear. Therefore, in order to abate the motor noise, we must study it.

So, in the first place, noise of a small three phase induction motor is divided into several component noises, and the ones influenced by ball bearings are found out; next, the influences of ball bearings are examined, lastly the causes of the influences are made clear in the present paper. As a result of the above studies, we can establish the most suitable treatment of ball bearings theoretically, and further obtain new knowledges on fitted ball bearing noise.

\section{On the experiment and noise measurement}

Experiments are done in a soundproof chamber $8 \mathrm{~m}$ long, $5 \mathrm{~m}$ wide, and $3 \mathrm{~m}$ high. Wall and ceiling

* Received 5th February, 1963.

** Research Fellow, Research Laboratory, Nippon Seiko Co., Ltd., Fujisawa. of the chamber are made of rock wool which has gocd soundproof quality. A testing motor is mounted on the vibration-preventing rubber which covers a testing iron plate in the chamber. The testing motor is a three phase $a-c$ induction motor ( $1 / 2$ horse power, 4 poles) equipped with ball bearings (bearing type 6303), as shown in Fig. 1(a). The motor is tested under no load, so that a ball bearing is loaded

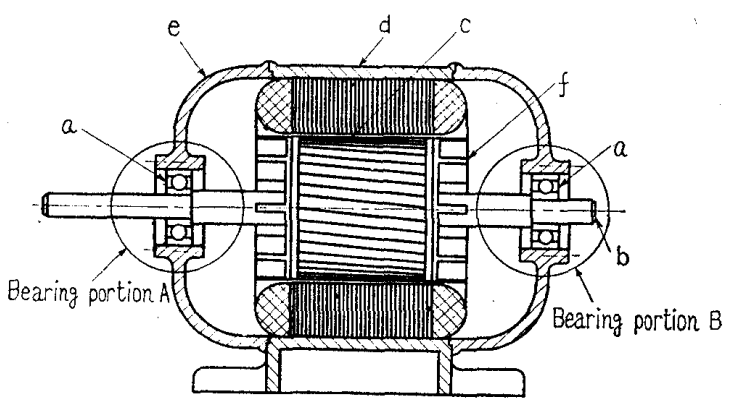

(a)

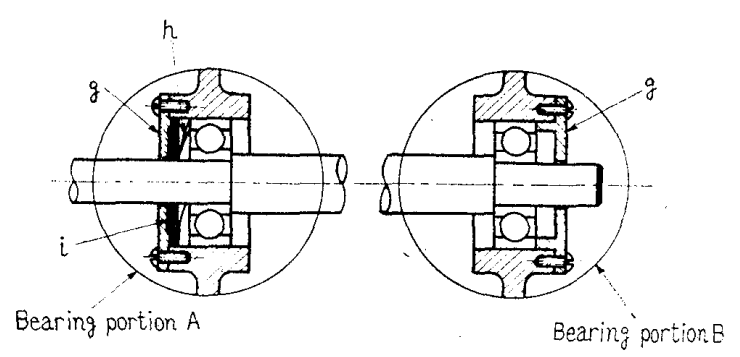

(b) Preloading of ball bearing

a: Ball bearing, b: Rotating shaft, c: Rotor,

d: Stator, e: Bracket, f: Fan, g: End cover,

h: Leaf spring, i: Shim

Fig. 1 Testing motor 
always with a radial load $(1.47 \mathrm{~kg})$ which equals a half of the rotor weight. To know the generating sources of the motor noise, the fans can be removed and the bearings can be changed to the ball bearings or the plain bearings. Moreover, the ball bearings are preloaded by using the leaf spring and the shims as shown in Fig. I (b). For the lubrication of the ball bearings: and the plain bearings, $\# 60$ spindle oil is used because it has a stability for the bearing noise. The rotating speed $N$ is varied by the frequency controlling A.C. power source.

In order to measure the motor noise, a microphone is set at four positions on the side face of the motor as shown in Fig. 2. The distance from the side face to the vibrating plate of the microphone is held $150 \mathrm{~mm}$ at all positions. Each position of the microphone is called as shown in Fig. 2. A noisemeasuring apparatus is arranged as shown in Fig. 3, and a condenser microphone, which has gocd frequency characteristics as shown in Fig. 4, is used to measure exactly the wide frequency noise.

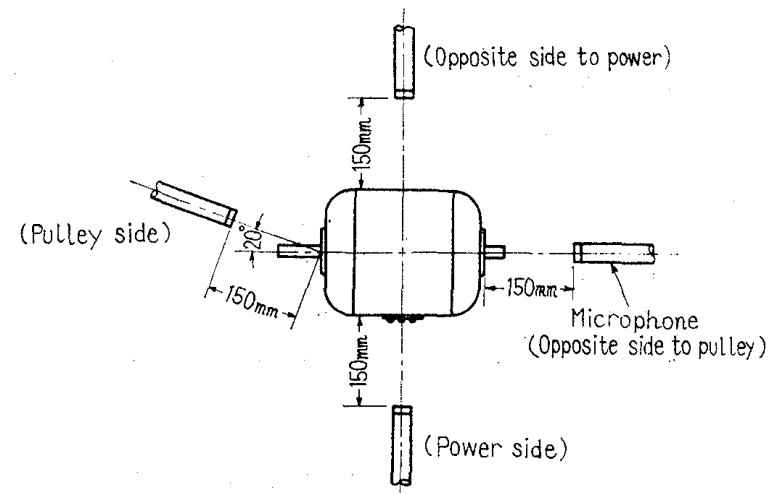

Fig. 2 Position of microphone

\section{Experimental results and analysis}

3.1 Frequency analysis of motor noise To divide the motor noise into some component noises, the motor noise must be analyzed on the frequency. Fig. 5 and Fig. 6 are the frequency spectrums of the testing motor noise on the opposite side to the power source; Fig. 5 (a) and (b) show the influences of the fan and the ball bearing respectively, and Fig. 6 is an example of the electromagnetic noise. These frequency spectrums always deviate a little even at the same experimental condition.

3.2 Classification of motor noise From the above frequency spectrums, we can know the properties of the component noises in the motor. Next, the generating sources of the component noises are

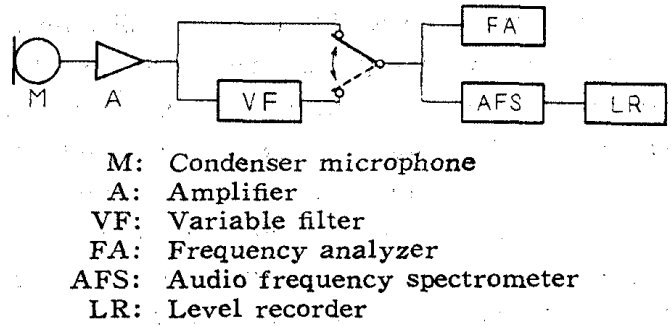

Fig. 3 Arrangement of noise-measuring apparatus

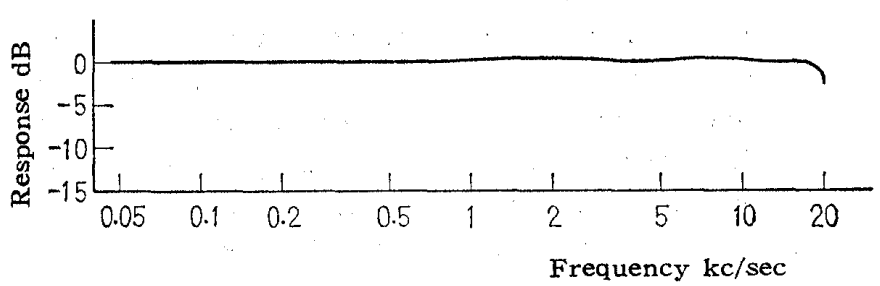

Fig. 4 Frequency characteristics of microphone
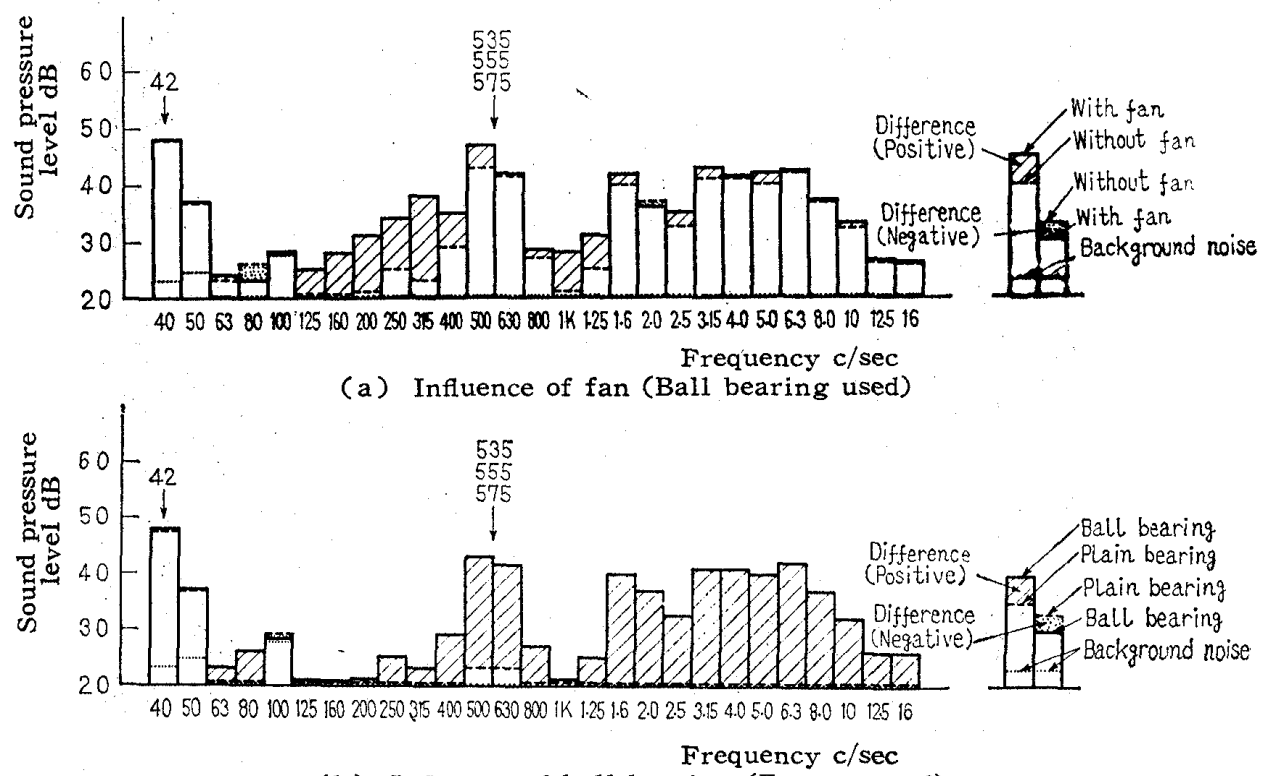

(b) Influence of ball bearing (Fan removed) (Opposite side to power, $N=2500 \mathrm{rpm}$ )

Fig. 5 Frequency spectrums of motor noise 
examined, and the motor noise is classified into the component noises.

(i) Rotating noise The first component noise is the noise having a frequency of $42 \mathrm{c} / \mathrm{sec}$ in Fig. 5 (a) and (b). This noise, having the same frequency of the rotating speed, does not disappear immediately by switching off the power source. Further, it appears strongly at the high rotating speed and on the opposite side to the power source and on the power side. From Fig. 5, we can know that the noise does not relate to the presence of the fans and the kinds of the bearing. From these many properties, it is considered that the noise is due to the dynamic unbalance of the rotor.

(ii) Stator resonant noise The second component noise is the noise having the frequencies of $535 \mathrm{c} / \mathrm{sec}, 555 \mathrm{c} / \mathrm{sec}$ and $575 \mathrm{c} / \mathrm{sec}$ in Fig. 5 (a) and (b). The noise, having almost constant frequencies at different rotating speeds, does not disappear immediately by switching off the power source. Moreover, it appears strongly at the high rotating speed and on the opposite side to the power source and on the power side. Although this kind of noise appears both in the case of the ball bearings and in the case of the plain bearings, the noise in the former grows stronger than that in the latter.

As the noise is assumed from the above properties to relate to the stator, the natural frequencies on the stator of the testing motor are examined by a sound of the stator. The results are shown in Fig. 7, and two kinds of the natural vibrations are found out. The first kind of the natural vibrations are ones of $536 \mathrm{c} / \mathrm{sec}, 556 \mathrm{c} / \mathrm{sec}_{y} 571 \mathrm{c} / \mathrm{sec}, 600 \mathrm{c} / \mathrm{sec}$,
$630 \mathrm{c} / \mathrm{sec}$ and $658 \mathrm{c} / \mathrm{sec}$; and it is confirmed by the calculations that these correspond to the first order radial bending natural vibration on the stator. The second kind of the natural vibrations are ones of $301 \mathrm{c} / \mathrm{sec}, 315 \mathrm{c} / \mathrm{sec}$ and $325 \mathrm{c} / \mathrm{sec}$; and it is assumed from the frequencies that these correspond to the $1 / 2$ order subharmonic vibrations of the above mentioned natural vibrations having the frequencies $600 \mathrm{c} / \mathrm{sec}, 630 \mathrm{c} / \mathrm{sec}$ and $658 \mathrm{c} / \mathrm{sec}$. As the frequencies $536 \mathrm{c} / \mathrm{sec}, 556 \mathrm{c} / \mathrm{sec}$ and $571 \mathrm{c} / \mathrm{sec}$ of the first kind agree well with those of the second component noise, it is considered that the noise is due to the first order radial bending natural vibrations on the stator. Therefore, we can assume through the above analysis that the cause of the noise is the vibrations of the bearing and the draft.

(iii) Ventilating noise The third component is the noise appearing over the frequency bands between $125 \mathrm{c} / \mathrm{sec}$ and $500 \mathrm{c} / \mathrm{sec}$ in Fig. 5 (a). The noise appears in the presence of the fans, and it

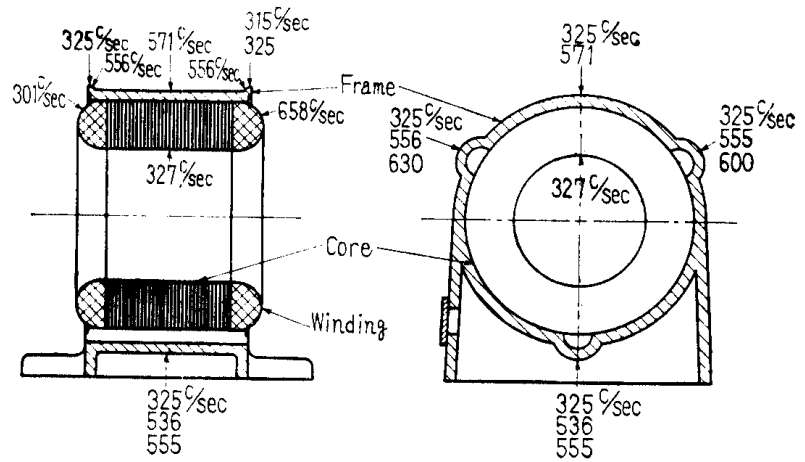

Fig. 7 Natural frequency on stator

(a)

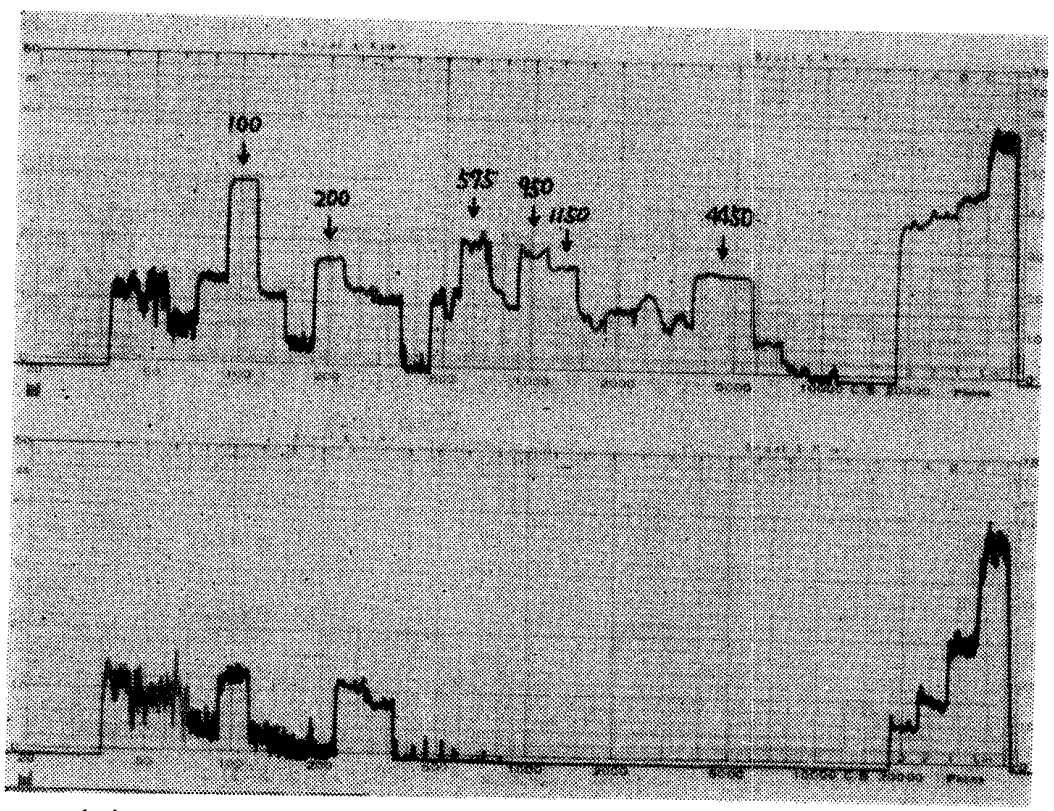

(a) Electromagnetic noise ( $\mathrm{Fan}^{-}{ }^{-}$removed, plain bearing used)

(b) Background noise

(Opposite side to power, $N=1500 \mathrm{rpm}$ )

Fig. 6 Frequency spectrum of motor noise 
seems that the noise has a middle frequency which is the prcduct of the rotating speed and the number of the fan blades. Similarly to the first and the second component noises, the third component does not disappear immediately by switching off the power source. Moreover, it appears strongly at the high rotating speed and on the opposite side to the pulley and on the pulley side. From the above properties, it is considered that the noise is due to the draft by the fans.

(iv) Bearing noise The fourth component is the noise having the frequencies above $1 \mathrm{kc} / \mathrm{sec}$ in Fig. 5 (a) and (b). From Fig. 5 (b), we can know that the noise appears in the presence of the ball bearings. Further, the noise does not disappear immediately by switching off the power source and appears strongly on the opposite side to the pulley and on the pulley side. The principal frequencies of the noise do hardly change with the higher rotating speed but the sound pressure level increases.

These are the same properties as of the fitted ball bearing noise ${ }^{(3)}$. By the above properties, it is considered that the noise is due to the ball bearings.

(v) Electromagnetic noise The fifth component is the noise having the frequencies $100 \mathrm{c} / \mathrm{sec}$, $200 \mathrm{c} / \mathrm{sec}, 950 \mathrm{c} / \mathrm{sec}, 1150 \mathrm{c} / \mathrm{sec}$ and $4450 \mathrm{c} / \mathrm{sec}$ in Fig. 6 (a). The noise appears unstably and disappears immediately by switching off the power source. Moreover, the noise can be subdivided into two kinds; one is the harmonics on the frequency of the power source $(100 \mathrm{c} / \mathrm{sec}$ and $200 \mathrm{c} / \mathrm{sec})$, another is the harmonics on the slot of the stator or the rotor $(950 \mathrm{c} / \mathrm{sec}, 1150 \mathrm{c} / \mathrm{sec}$ and $4450 \mathrm{c} / \mathrm{sec}$ ). It is well known that the causes of the noise are induced by the eccentricity of the rotor to the stator and the variations of the radial magnetic field ${ }^{(4)}$.

Now, from the above, we can summarize the classification of the motor noise as shown in Table 1 . The frequency values in the Table are obtained from the present experiments. From the Table, it

Table I Classification noise of small three phase a-c induction motor

\begin{tabular}{|c|c|c|}
\hline $\begin{array}{l}\text { Kinds of } \\
\text { component noise }\end{array}$ & $\underset{\text { Frequency }}{\mathrm{c} / \mathrm{sec}}$ & Generating cause \\
\hline Rotating noise & $\begin{array}{l}\text { Rotating } \\
\text { speed }\end{array}$ & Dynamic unbalance of rotor \\
\hline $\begin{array}{l}\text { Electromagnetic } \\
\text { noise }\end{array}$ & $\begin{array}{l}100, \quad 200 \\
950,1150 \\
4450\end{array}$ & $\begin{array}{l}\text { Eccentricity of rotor to } \\
\text { stator and variations of } \\
\text { radial magnetic field }\end{array}$ \\
\hline Ventilating noise & $160 \sim 500$ & Air draft by fan \\
\hline $\begin{array}{l}\text { Stator resonant } \\
\text { noise }\end{array}$ & $500 \sim 630$ & $\begin{array}{l}\text { Natural vibrations of stator } \\
\text { due to vibrations of bearing } \\
\text { and air draft }\end{array}$ \\
\hline Bearing noise & $\begin{array}{c}\text { Above } \\
1000\end{array}$ & Ball bearing \\
\hline
\end{tabular}

is understocd that the component noises relating to the ball bearings are the stator resonant noise and the bearing noise, and they extend over the most sensitive frequency range of the human ear. Therefore, we will take up the above two component noises and make the experiments in the case without fans at the following sections in which the influences. on the ball bearings are examined.

To measure the stator resonant noise, the bearing noise and the sum noise of the above two component noises, a variable filter in Fig. 3 is used.

By means of the variable filter, three filters having. the frequency characteristics as shown in Fig. 8 are made. We will use the band pass filter $A$ for the stator resonant noise, the high pass filter $B$ for the bearing noise and the high pass filter $\mathrm{C}$ for the sum noise of the stator resonant noise and the bearing. noise.

3.3 Influences of preload, radial clearance and rotating shaft vibration Although the influences of the preload and the radial clearance of the ball bearings on the motor noise were examined partially up to the present time ${ }^{(2)}$, they are not well known systematically. In this section, we will examine minutely the above influences, and make clear the causes of the influences.

In the first place, to know the influence of the preload of the ball bearings, the motor noises in the experiments, in which the preload $T$ is varied and the radial clearance after mounting* $e_{r}$ is kept constant, are measured. The experimental results are shown in Fig. 9 and Fig. 10; Fig. 9 represents.
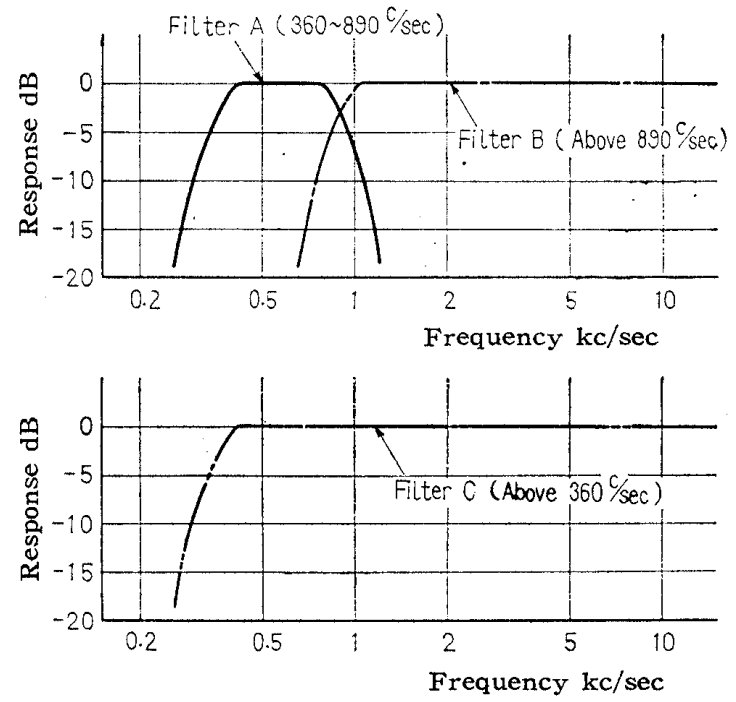

Fig. 8 Frequency characteristics of filters

* A radial clearance which remains in a ball bearing fitted in the housing and at the end of a shaft. This clearance takes no account of elastic deformation of the ball bearing due to the shaft weight etc. The values of the clearance are obtained by calculations. in the present report. 
the relations of the principal frequencies of the motor noise and the preload and Fig. 10 the relations of the sound pressure level of the noise and the preload. In Fig. 10, the mean value and the fluctuating range of the sound pressure levels are plotted, as the stator resonant noise is unstable.

From Fig. 9, it is known that the principal frequencies of the motor noise increase a little with the preload and the high principal frequencies (the bearing noise) on the opposite side to the pulley increase more than those on the opposite side to the power source. Moreover, the principal frequencies in Fig. 9 correspond to the bending natural frequencies on the stator and the natural frequencies on the outer ring of the ball bearing, because they almost coincide to the first order radial bending natural frequency on the stator $f_{s}$, the natural frequency of a vibratory system which consists of a mass of the outer ring and an axial stiffness of the ball bearing $f_{A M}$, the first order radial bending natural frequency on the outer ring of the ball bearing $f_{R 1}$ and the first order axial bending natural frequency on the outer ring of the ball bearing $f_{A 1}$, respectively.

Now, from Fig. 10, we can know the following properties of the stator resonant noise and the bear- ing noise.

(1) The stator resonant noise appears strongly on the opposite side to the power source, the bearing noise does on the opposite side to the pulley.

(2) The stator resonant noise increases with the radial clearance after mounting, but the bearing noise decreases with it.

(3) The bearing noise increases and saturates gradually with the preload, but the stator resonant noise does hardly change with it.

(4) However, if a small preload is applied to the ball bearings with a large radial clearance after mounting, the stator resonant noise and the bearing noise decrease abruptly with the preload.

Then, we will make clear the causes in the following. First, it is supposed that the property (1) is due to the motor's structure. Next, we can reason that (2) and (3) are due to the properties of the stator resonant noise and the bearing noise. The stator resonant noise increases with the radial clearance because the noise relates to the vibrations of the bearings. Further, the bearing noise in this case has the same properties as of the noise of the simple ball bearing with the axial load(5)(6).

Lastly, as it is supposed that the property (4)
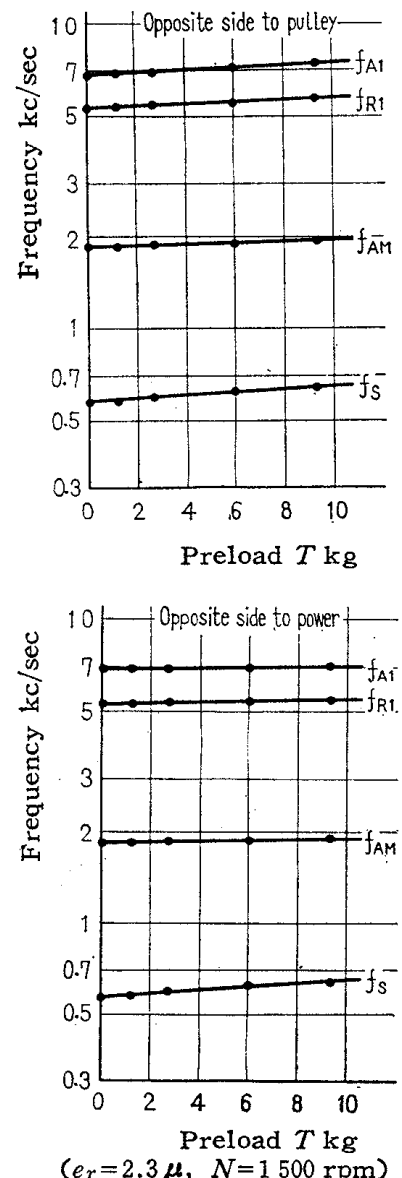

Fig. 9 Relations of principal frequency and preload

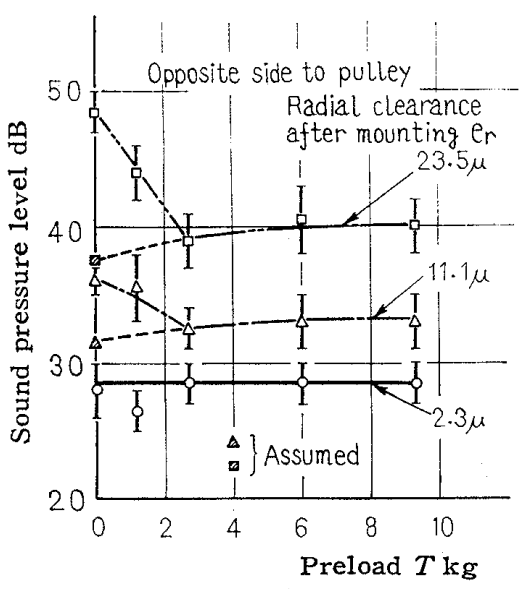

(a) Stator resonant noise $(360 \sim 890 \mathrm{c} / \mathrm{sec})$
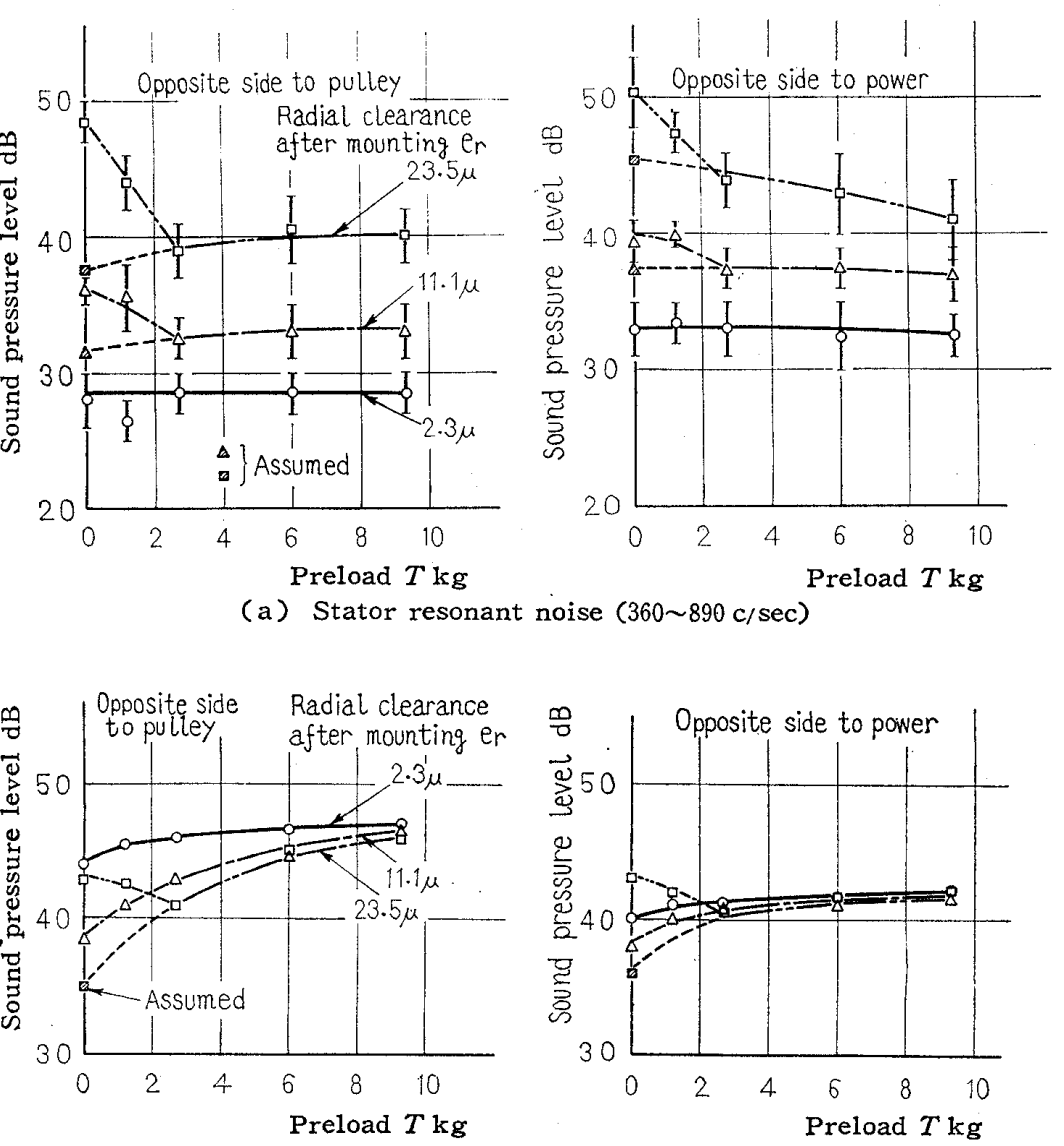

(b) Bearing noise (above $890 \mathrm{c} / \mathrm{sec}$ )

Fig. 10 Relations of sound pressure level and preload $(N=1500 \mathrm{rpm})$ 
relates to the vibration of the rotating shaft, some experiments, which examine the relations between the sound pressure levels of the stator resonant noise and the bearing noise and the amplitude of the rotating shaft vibration in the case of no preload, are carried. The radial vibration of the rotating shaft is measured by an Auto-dyne type converter in which a variation of electrostatic capacity due to the clearance between the head and the rotating shaft is converted into an electric current. By the above experiments, it is made clear that all radial vibrations in the present case have the same frequency of the rotating speed $(25 \mathrm{c} / \mathrm{sec})$. An example of the experimental results in the case of the largest radial clearance after mounting is shown in Fig. 11, and we shall see the relations between the sound pressure levels of the stator resonant noise and the bearing noise and the amplitude of the rotating shaft vibration. Now, we can assume a sound pressure level under no vibration of the rotating shaft, but such does not exist practically. For reference, the assumed sound pressure levels are plotted in Fig. 10, too.

From the above analysis, it is made clear that the property (4) is due to the vibration of the rotating shaft. So, if a small preload is applied to the ball bearings, the stator resonant noise and the bearing noise decrease abruptly since the vibration disappears. This circumstance can be explained by Fig. 12. The sound pressure level of two component noises in the case of the large radial clearance after mounting traces a line UVW with the preload. But, as the line between $U$ and $V$ is due to the vibration of the rotating shaft, the line in the case of no vibration changes as a line $\mathrm{XVW}$ with the preload.

Next, in order to know the influence of the

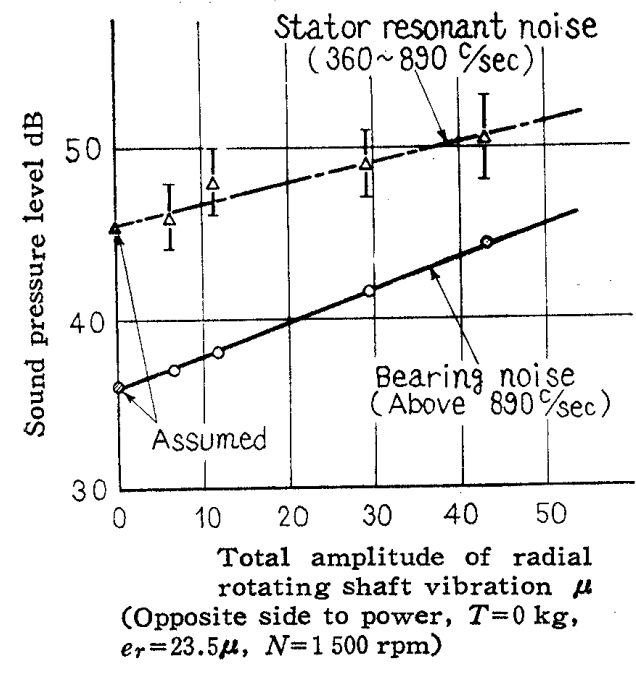

Fig. 11 Relation of sound pressure level and rotating shaft vibration radial clearance after mounting of the ball bearing, the motor noises in the experiments, in which the radial clearance is varied in some steps and the preload is zero, are measured. The results of the experiments are shown in Fig. 13 (a), and those of the case of no vibration of the rotating shaft are represented in Fig. 13 (b). But, in Fig. 13 (b), values of the assumed sound pressure level in Fig. 10 are used, and the fluctuating range of the sound pressure level of the stator resonant noise is omitted. From Fig. 13, we can know the following properties of the stator resonant noise and the bearing noise.

(1) In the case of no vibration of the rotating shaft, the stator resonant noise increases with the radial clearance after mounting, but the bearing noise decreases with it.

(2) The influence of the vibration of the rotating shaft appears at the range of positive radial clearance after mounting. If a vibration exists, the increasing rate of the stator resonant noise with the radial clearance after mounting increases, and the bearing noise in the case of a large radial clearance after mounting increases.

(3) By the properties (1) and (2), the sum noise of the stator resonant noise and the bearing noise has minimum sound pressure level at a radial clearance (Point $P$ ), and $P$ moves to zero with the amplitude of the vibration of the rotating shaft.

We must take notice of the property (3) to decrease the motor noise without a preload. As $P$ is decided by the sound pressure level- the radial clearance after mounting characteristics of the stator resonant noise and the bearing noise, it is assumed that $\mathrm{P}$ takes different positions according to the size and structure of the motor.

The properties (1) and (2) tell us important properties of the fitted ball bearing noise. A horizontal rotating shaft which is supported by two ball bearings with a large radial clearance after mounting is liable to vibrate. But, the standard case for the fitted ball

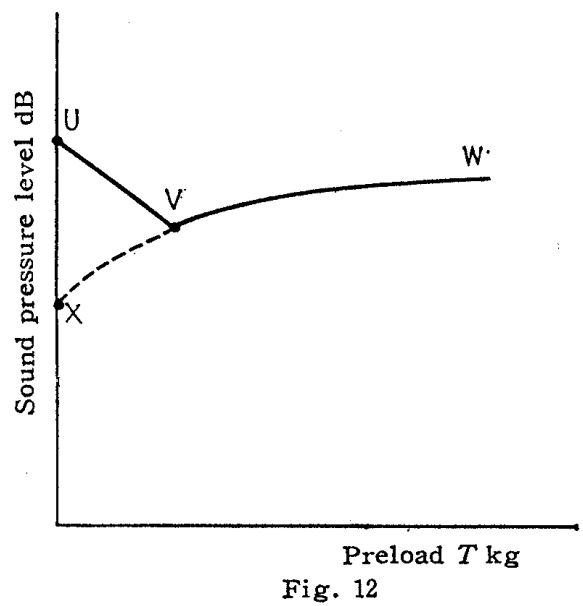


bearing noise is that of no vibration of the rotating shaft. As the property (1), the bearing noise in the standard case decreases with the radial clearance after mounting. This property is found out in a study on the ball bearing noise, too ${ }^{(7)}$.

3.4 Influence of rigidity of bracket (or housing) It is known that the motor noise is influenced by the rigidity of the bracket ${ }^{(1)}$. However, the influences of that have not been made clear till the present time. Then, we will examine minutely the influences of the rigidity of the bracket on the motor noise and make clear their causes in the present section.

To vary the rigidity of the bracket, an axial thickness of the molded bracket is changed in three steps as shown in Fig. 14. The experiments are done by using the above brackets and changing the rotating speed, and the motor noise is measured.

The experimental results are shown in Fig. 15 (a) and (b), but the fluctuating range of the stator resonant noise in (a) is omitted.

We can notice two peaks $Q_{1}$ and $Q_{2}$ in Fig. 15.
The rotating speeds of the peaks $Q_{1}$ and $Q_{2}$ relate to the natural frequencies on the stator; the rotating speed $(44.7 \mathrm{c} / \mathrm{sec})$ of the peak $Q_{1}$ corresponds to about $1 / 7$ of the natural frequency of $315 \mathrm{c} / \mathrm{sec}$ and the rotating speed $(77.3 \mathrm{c} / \mathrm{sec})$ of the peak $Q_{2}$ corresponds to about $1 / 7$ of that of $536 \mathrm{c} / \mathrm{sec}$ (See Fig. 7). It is known that the harmonic vibrations, of which the frequency is equal approximately to odd number times the rotating shaft speed, appear often in the small induction motors equipped with ball bearings ${ }^{(8)}$. So, we can consider that the peaks $Q_{1}$ and $Q_{2}$ are due to the resonances of the harmonic vibrations on the rotating speed and the stator.

Further, we can notice the high sound pressure level of the stator resonant noise in the case of the thickness being $2 \mathrm{~mm}$. This is the cause of axial natural vibration on the bracket.

Next, we can know from Fig. 15 (b) that the bearing noise increases with the rotating speed and the rate of noise increase with the rotating speed decreases with the thickness of the bracket. These influences of the thickness of the bracket appear
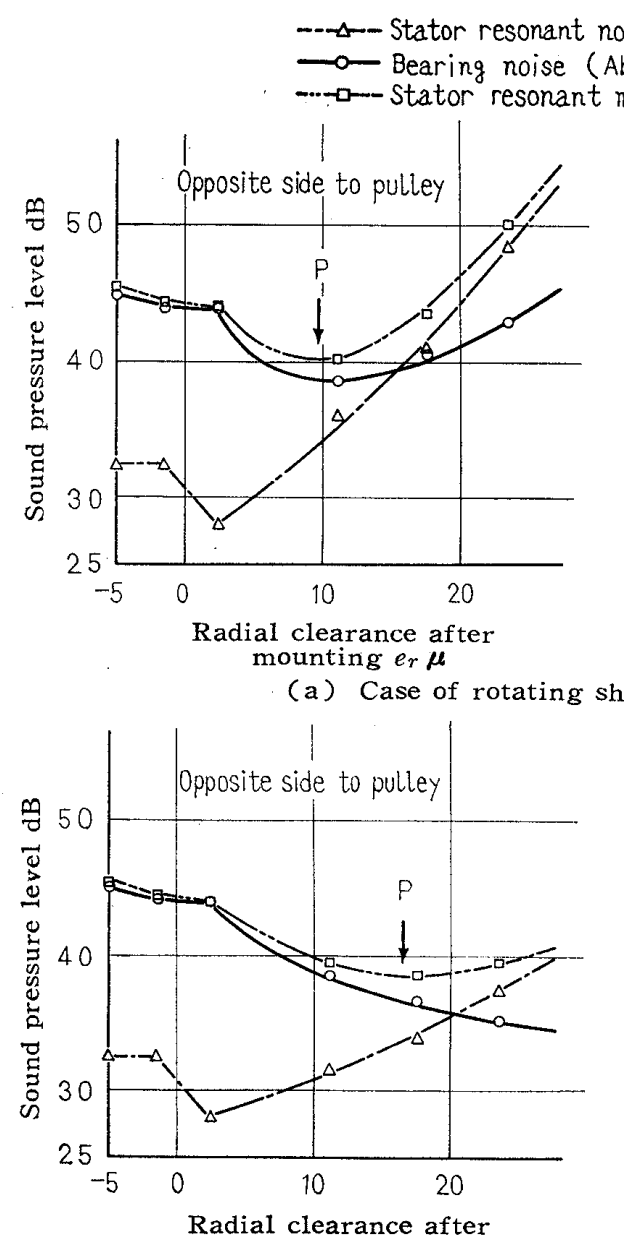

ing er

(a) Case of rotating shaft vibration generated

Radial clearance after mounting er $\mu$

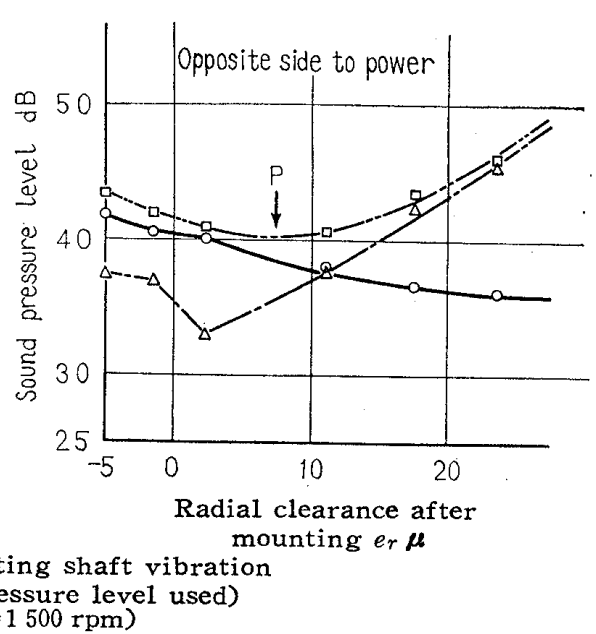

(Assumed soun $(T=0 \mathrm{~kg}, N=1500 \mathrm{rpm})$

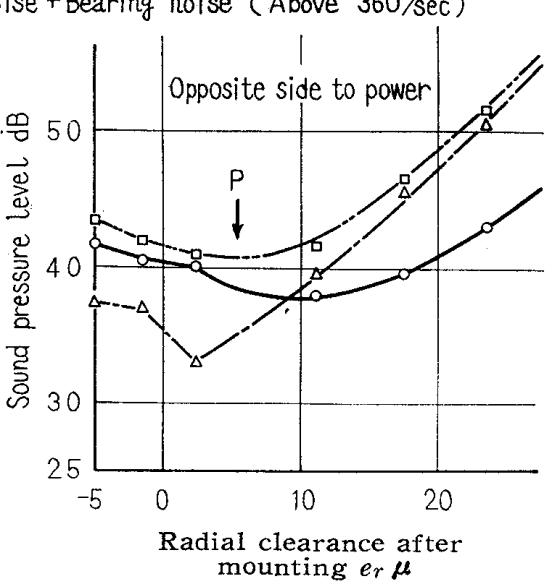

Fig. 13 Relations of sound pressure level and radial clearance

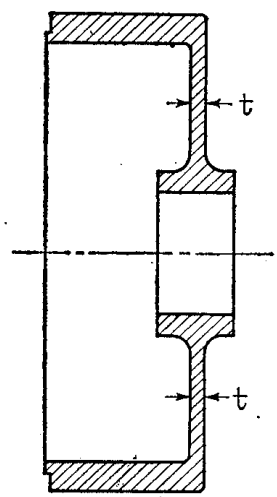

$(t=2,5,10 \mathrm{~mm})$

Fig. 14 Bracket 
clearly on the opposite side to the pulley. Here, we will obtain the slope at the linear portion of the left side curves in Fig. 15 (b). The results are plotted in Fig. 16, and it is understood from the graph that the increment of the sound pressure level of the bearing noise with the rotating speed decreases abruptly with the thickness of the bracket. The value

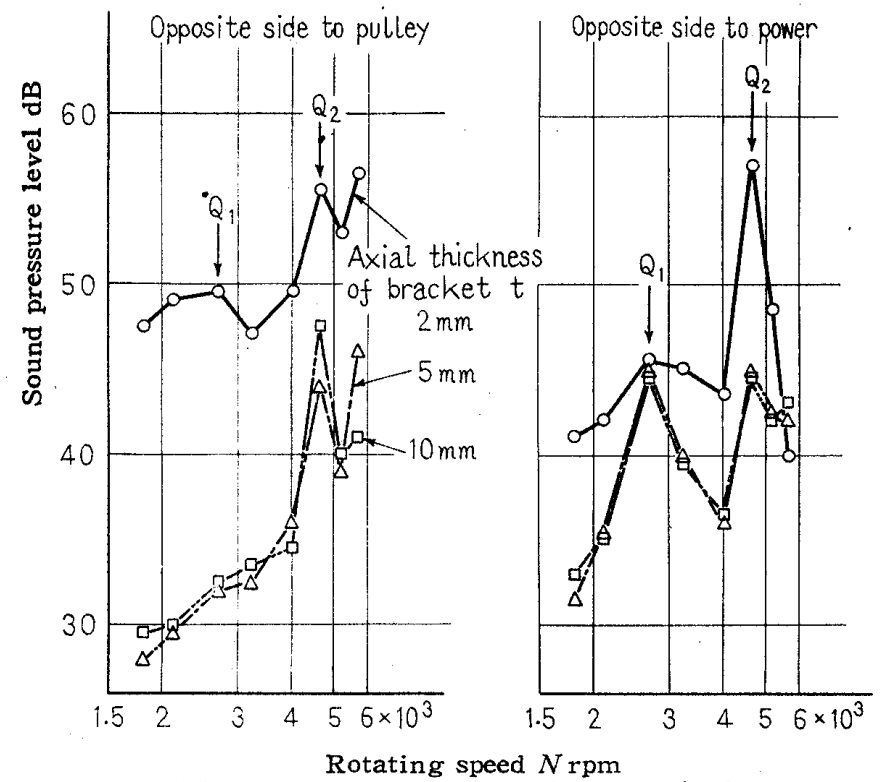

(a) Stator resonant noise $(360 \sim 890 \mathrm{c} / \mathrm{sec})$

$\left(T=0 \mathrm{~kg}, e_{r}=2.3 \mu\right)$

at zero thickness in Fig. 16 is obtained from Fig. 17 which shows the measured result of the simple ball bearing noise under the same measuring condition of the motor noise.

Through the above analysis, it is considered that the high rigidity bracket can damp the bearing noise.

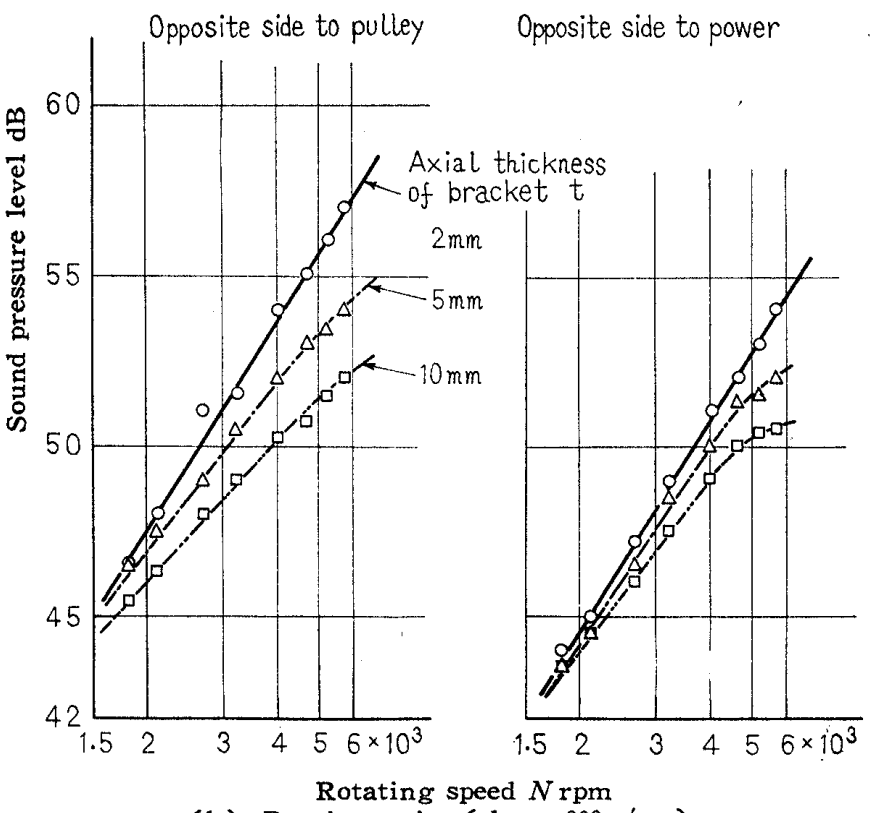

(b) Bearing noise (above $890 \mathrm{c} / \mathrm{sec}$ )

Fig. 15 Relations of sound pressure level and rotating speed

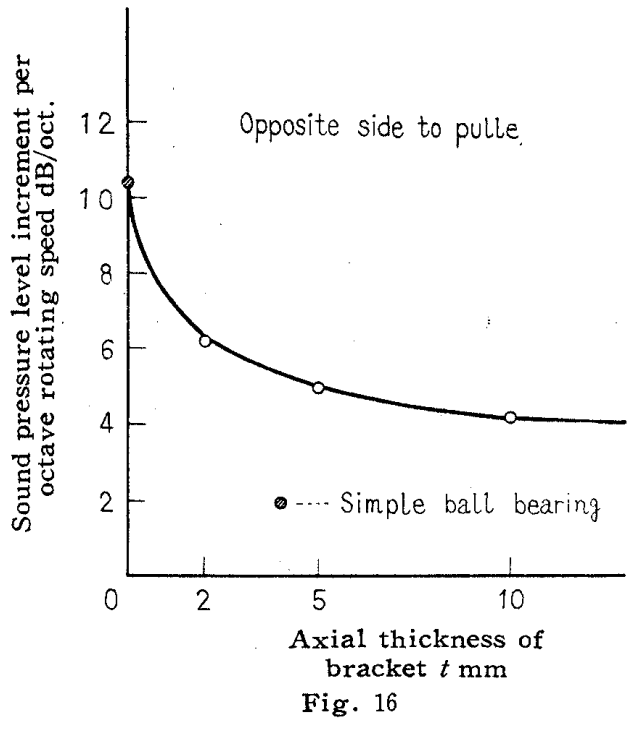

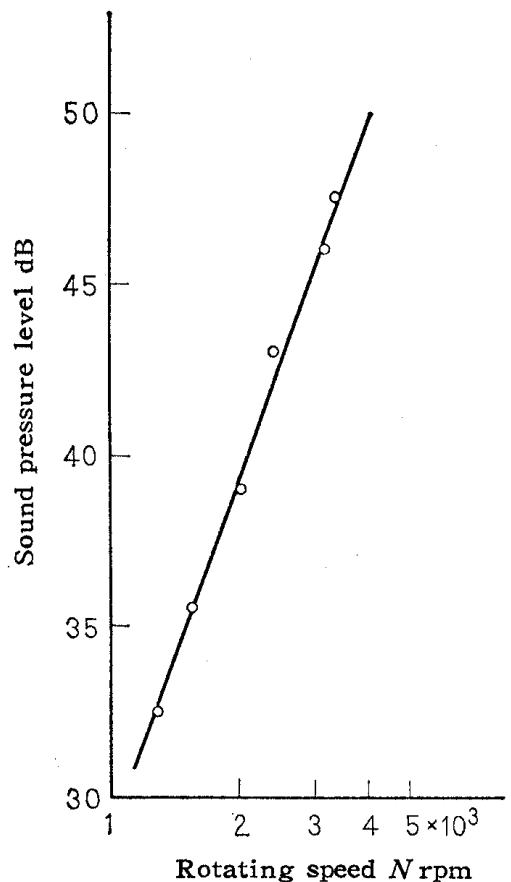

(6303, radial real clearance*: $2.4 \mu$, radial load: $1.47 \mathrm{~kg}$, filter $B$ used)

* A radial clearance which can be obtained by deducting elastic deformation of a ball bearing for measuring from the radial measured clearance

Fig. 17 Relation of sound pressure level and rotating speed (Case of simple ball bearing) 


\section{Considerations}

4.1 On noise of three phase a-c induction motor In the above section, it is made clear that the noise of a small three phase $a-c$ induction motor is divided into the rotating noise, the electromagnetic noise, the ventilating noise, the stator resonant noise and the bearing noise; and the bracket resonant noise appears in the case of the low rigidity brackets, too. As these component noises are influenced by the size, the structure and the electrical characteristics of the motor, it is assumed that the generation of the component noises depends on the kind of the motor. In the case of a large three phase a-c induction motor, the stator resonant noise appears strongly ${ }^{(9)(10)}$.

$4 \cdot 2$ On noise of fitted ball bearing The noise of the fitted ball bearing is influenced by many factors. From the present report and some previous reports $^{(2)(8)(7)}$, the following factors are found out:

(1) Lubricant, (2) rotating speed, (3) load, (4) radial clearance, (5) vibration of rotating shaft, (6) fitting of race rings, and (7) rigidity of housing.

\section{Conclusions}

(1) The noise of a small three phase a-c incuction motor is divided into the rotating noise, the electromagnetic noise, the ventilating noise, the stator resonant noise and the bearing noise. In addition to these, the bracket resonant noise appears in a motor with low rigidity brackets.

(2) Among the above component noises, the stator resonant noise and the bearing noise relate to the ball bearings.

(3) The stator resonant noise and the bearing noise relate to the rotating shaft vibration which has the same frequency of the rotating speed, and their sound pressure levels increase with the amplitude of the vibration. The vibration appears in the case of a large radial clearance after mounting, but disappears abruptly when a small preload is applied.
(4) The sound pressure level of the sum gise of the stator resonant noise and the bearing noise takes a minimum value at a small positive radial clearance after mounting.

(5) The stator resonant noise and the bearing noise are influenced by the preload and the radial clearance after mounting. Their principal frequencies increase with the preload. Moreover, the sound pressure level of the stator resonant noise increases with the radial clearance after mounting, and that of the bearing noise increases with the preload, decreases with the radial clearance after mounting. This is the same property as of the simple ball bearing noise.

(6) The bearing noise is influenced by the rigidity of the bracket, and the increasing rate of the sound pressure level with the rotating speed decreases with the rigidity of the bracket. Therefore, it is considered that the high rigidity bracket can damp the bearing noise.

\section{Acknowledgement}

The author wishes to express his hearty thanks to Mr. Hideo Ōkoshi of Nippon Seiko Co. Ltd., for his kind advices and cooperations with the present research.

\section{References}

(1) G. Lohmann: Konstruktion, Jg. 5, Ht. 3 (1953), S. 85 .

(2) M. Unterberger: $V D I-Z$, Bd. $98, \mathrm{Nr} .6$ (1956), S. 209.

(3) T. Igarashi: Bulletin of JSME, Vol. 5, No. 17 (1962), p. 184.

(4) C. M. Harris: Handbook of Noise Control (1957), 30.2, McGraw-Hill.

(5) K. Tanaka: Science of Machine (Japanese), Vol. 9, No. 6 (1957), p. 683.

(6) T. Igarashi: Trans. Japan Soc. Mech. Engrs., Vol. 26, No. 166 (1960), p. 833.

(7) T. Igarashi: Trans. Japan Soc. Mech. Engrs., Vol.28, No. 193 (1962), p. 1168

(8) T. Igarashi: Bulletin of JSME, Vol. 3, No. 9 (1960), p.81.

(9) P. L. Alger and E. Erdelyi: Jour. Acous. Soc. Amer., Vol. 28, No. 6 (1956), p. 1063

(10) E. Erdelyi and G. Horvay: Jour. Appl. Mech., Vol. 24 , No. 1 (1957), p. 39. 